\title{
Identidades e Epistemologias: \\ A Lei 10639/03 na Descolonização da Escola ${ }^{1}$
}

\author{
SOUZA, Gasperim Ramalho de ${ }^{2}$ \\ ROQUE, Arnaldo César ${ }^{3}$
}

\section{RESUMO}

Este artigo tem como objetivo apresentar algumas contribuições da lei 10639/03 que estabelece diretrizes educacionais para o ensino de História e Cultura da Africa e dos africanos seus diálogos para uma educação intercultural crítica. Dessa forma, enquanto principal eixo didático-metodológico dessa lei, propomos a educação intercultural crítica, a qual prioriza a valorização da identidade cultural afro-diaspórica e do continente, como ferramentas epistemológicas, visando uma resistência ao branqueamento e apagamento dessas identidades no cenário educacional. Esse apagamento ainda é persistente através do mito da democracia racial e outros discursos que podem ser endossados por educadores que não utilizam a referida lei como um importante suporte para leitura e ação diante de documentos norteadores na educação brasileira tal como a Base Nacional Comum Curricular (BNCC).

Lei 10369/03. Educação Intercultural. Identidades Afro-Diaspóricas.

\section{Identities and Epistemologies: Law 10639/03 on School Decolonization}

\section{ABSTRACT}

This article aims to present some contributions of 10639/03 Act, which establishes educational rules for the teaching of history and culture of Africa and Africans, and their dialogues for an intercultural education. Thus, while the main didactic-methodological axis of this law proposed the critical intercultural education, which prioritizes the valuation of cultural-diasporic cultural identity and

\footnotetext{
${ }^{1}$ Este artigo é resultado das leituras realizadas durante a primeira etapa da pesquisa Denominada Por uma Pretagogia no Livro Didático de Língua Portuguesa e Inglesa: Uma Análise da (Não) Aplicação da Lei 10639/03, sob orientação do Professor Gasperim Ramalho de Souza durante o Programa Institucional de Iniciação Científica Voluntária (PIVIC) da Universidade Federal de Lavras (UFLA), no ano de 2016.

${ }^{2}$ Doutorando em Estudos da Linguagem pelo Centro Federal e Tecnológico de Minas Gerais (CEFET-MG). Mestre em estudos Linguísticos (UFMG). Professor do Departamento de Estudos da Linguagem (DEL) da Universidade Federal de Lavras (UFLA). Email: gasperim.souza@ufla.br. Lattes: http://lattes.cnpq.br/7600693416505639. Orcid: 0000-00032060-1826.

${ }^{3}$ Graduado em Letras - Português/Inglês pela (UFLA). Email: roquearnaldoc@gmail.com. Lattes: http://lattes.cnpq.br/9775934518233592. Orcid: 0000-0003-2575-3087.
} 
towards continent, as epistemological tools, aiming at resisting to bleaching and deletion of those identities in the educational setting. That deletion process still remains through racial democratic myth and other discourses which can be endorsed by educators who do not rely on the aforementioned act as an important basis for reading and acting towards the implementation of the Brazilian National Curriculum as a guiding educational document.

10639/03 Act. Intercultural Education. African-Diasporic Identities.

\section{Identidades y epistemologías: Ley 10639/03 en la descolonización de la escuela}

\section{RESUMEN}

Este artículo tiene como objetivo presentar algunos aportes de la Ley 10639/03 que establece pautas educativas para la enseñanza de la Historia y Cultura de Africa y de los africanos sus diálogos para una educación intercultural crítica. Así, como principal eje didáctico-metodológico de esta ley, proponemos la educación intercultural crítica, que prioriza la valorización de la identidad cultural afro-diaspórica y del continente, como herramientas epistemológicas, apuntando a una resistencia al blanqueamiento y borramiento de estas identidades en el escenario educativo. Este borramiento aún persiste a través del mito de la democracia racial y otros discursos que pueden ser avalados por educadores que no utilizan la referida ley como un soporte importante para la lectura y la actuación frente a documentos orientadores en la educación brasileña como la Base Curricular Común Nacional (BNCC).

Ley 10369/03. Educación Intercultural. Identidades Afro-Diaspóricas.

\section{Identità ed epistemologie: Legge 10639/03 sulla decolonizzazione della scuola}

\section{SOMMARIO}

Questo articolo si propone di presentare alcuni contributi della Legge 10639/03 che stabilisce le linee guida educative per l'insegnamento della Storia e della Cultura dell'Africa e degli Africani i loro dialoghi per un'educazione interculturale critica. Pertanto, come principale asse didattico-metodologico di questa legge, proponiamo l'educazione interculturale critica, che privilegia la valorizzazione dell'identità culturale afro-diasporica e del continente, come strumenti epistemologici, indicando una resistenza allo sbiancamento e alla cancellazione di queste identità nel contesto educativo. Questa cancellazione persiste ancora attraverso il mito della democrazia razziale e altri discorsi che possono essere approvati da educatori che non usano la suddetta legge come un importante supporto per leggere e agire contro i documenti guida nell'educazione brasiliana come il Common Curriculum Base Nazionale (BNCC).

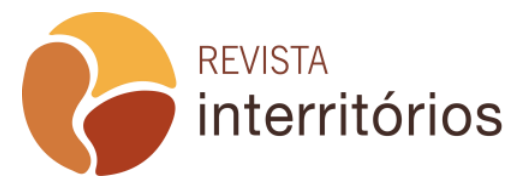

Interritórios | Revista de Educação Universidade Federal de Pernambuco, Caruaru, BRASIL | V.6 N.12 [2020] 
Legge 10369/03. Educazione interculturale. Identità afro-diasporiche.

\section{INTRODUÇÃO}

No Brasil, percebe-se que no que tange o legado negro-africano, há, ainda, certas resistências para a adoção de práticas pedagógicas que reconheçam, valorizem e fomentem ações a favor das contribuições dos saberes africanos para a construção dos conteúdos em sala de aula, tais como para aspectos epistemológicos. Com isso, infere-se ser necessária a superação de uma "tendência generalizada de considerarmos qualquer que seja 0 conhecimento relativo à África mais como objeto de pesquisa do que como uma possível contribuição à pesquisa" (CASTRO, 2005, p.15). A persistência desse fato tenciona, ainda mais, a postura eurocêntrica tanto da academia quanto da sociedade, o que elucida a emergente necessidade de práticas antirracistas que mirem a uma educação descolonizada em que as vozes africanas encontrem mais espaços para ecoarem e serem escutadas.

Ainda, conforme os últimos estudos feitos pela Organização das Nações Unidas (ONU, 2013), e do Instituto de Pesquisa Econômica Ampliada (IPEA, 2019), Atlas da Violência, percebe-se como o racismo no Brasil emerge e se sustenta a partir da ordem em que são mantidas imbricadas três instâncias distintas, mas interconexas e interdependentes: o simbólico, o sistêmico e o ideológico (MOORE, 2007). O racismo, dessa forma é estruturante na sociedade brasileira ao mesmo tempo em que é institucionalizado, o qual não só subjuga a sua maioritária população, de afrodescendentes (MOORE, 2007), como também sentencia esses sujeitos a um estado de genocídio e marginalização continuada: nas taxas de assassinados os negros, no Brasil, estão expressivamente dentre aqueles que são as maiores vítimas, ainda, é essa parte da população que tem a menor taxa de escolaridade, menores salários, maior taxa de desemprego, menor acesso à saúde, morrem mais cedo e têm a menor participação no Produto Interno Bruto. Compõem também a parte mais representada nas prisões. As prisões enquanto espaço de "punição" refletem um sistema penal que criminaliza indivíduos mostrando que a "seletividade é marca estrutural desse empreendimento" (FLAUSINO, 2006, p.32). Além disso, eles são os que ocupam menos postos no governo, ademais, os jovens negros são maioria nos casos de suicídio no Brasil.

A óptica supracitada tenciona, ainda mais, os percursos da docência e dos discentes no Brasil, uma vez que, sob esse viés, a educação passa a ser moldada , omitindo fatos históricos; não estudando a matriz africana no mundo, bem como desprezando sua história milenar, e suas produções científicas; estereotipando as experiência negras; e insistindo no ensino único e/ou

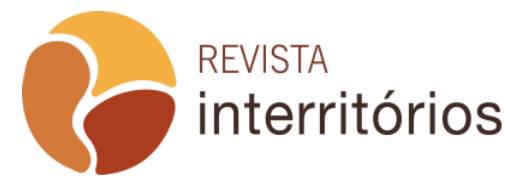

Interritórios | Revista de Educação Universidade Federal de Pernambuco, Caruaru, BRASIL | V.6 N.12 [2020] 
romantizado da escravização dos africanos do continente e em diáspora. Diante desse impasse, surge a necessidade de garantir que a História e Cultura AfroBrasileira e Africana fosse contada livre de quaisquer estereótipos e omissões, a fim de promover uma educação emancipadora que reconhecesse a temática do negro ao passo que abarcasse a diversidade na constituição da nação, e as contribuições de diferentes nacionalidades na estruturação de sua população. Nesse sentido, em 2003, surgiu a Lei 10.639/03, a qual altera a lei de diretrizes e bases adicionando a mesma a obrigatoriedade do ensino da cultura e história africana e afro-brasileira na educação para as relações étnico-raciais.

Posto isso, o objetivo deste artigo é analisar de que maneira a Lei 10.639/03 corrobora para a (re)constituição das identidades na diáspora africana, e para o fomento de ideias de pertencimento. Para tal, foi feita uma revisão bibliográfica acerca do tema em tela: as reflexões desenvolvidas neste trabalho, de caráter qualitativo, são provenientes da releitura da lei 10639/03 em consonância com as ideias de Rocha (2007), referente à Educação Antirracista; de Nobles (2009) e Nascimento (2002; 2017), acerca da (re)constituição das identidades e das experiências africanas no continente e na diáspora; em Fleuri (1999) e Hall (2006), no que se refere a uma perspectiva de ensino intercultural crítico; e em Moore (2007) e Munanga (2007), acerca do fenômeno do racismo; entre outros. As leituras realizadas nos possibilitaram aprofundar o olhar sobre a lei 10369/03 avultando seu potencial pedagógico para a valorização de uma educação antirracista, na medida em que centra suas proposições nas produções e experiências africanas e afro-diaspóricas como ferramenta epistemológica: seja ela social ou política.

\section{Cada pedaço de chão, cada pedra fincada, cada pedaço de mim: história e cultura africana nas escolas}

A escola é um dos espaços das construções de conhecimento, e, de identidades, visto que é um dos locais onde os alunos se (re)conhecem e se constituem enquanto sujeitos. Portanto, o direito à educação de qualidade precisa ser notado como imprescindível por todos os cidadãos, independente de raça, identidade, gênero, condição sexual, credo ou classe. Contudo, embora prescrita por lei, percebe-se, a partir de "recentes estatísticas, produções teóricas e pesquisas acadêmicas", que o racismo presente na sociedade brasileira "também se encontra refletido nos sistemas de ensino" (ROCHA, 2007, p. 10), em que esse reflexo se faz sentir tanto na esfera do acesso e permanência, quanto da composição curricular. Esse fator, portanto, prejudica a qualidade de educação almejada. A educação que endossamos é uma educação de caráter crítico, ancorada em epistemologias africanas que vai além de uma descolonização vazia que não permite 0 protagonismo das epistemes e

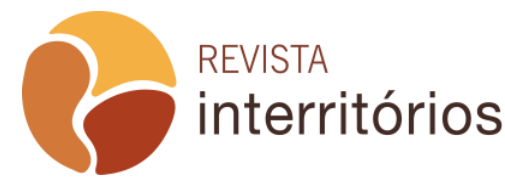

Interritórios | Revista de Educação Universidade Federal de Pernambuco, Caruaru, BRASIL | V.6 N.12 [2020] 
identidades estudantis, especialmente em se tratando de alunos negros ${ }^{4}$. Essa educação valoriza as identidades culturais como "aspectos de nossas identidades que surgem de nosso 'pertencimento' a culturas étnicas, raciais, linguísticas, religiosas e, acima de tudo, nacionais" (HALL, 2006, p.9).

Embora o Brasil seja formado a partir de diversas culturas, como as dos povos originários ${ }^{5}$, dos africanos e dos europeus, nos aparelhos educacionais, como em toda a dinâmica social, essas três forças não são valorizadas e reconhecidas da mesma maneira. Há, devido à colonização por meio de seu projeto higienista/genocida, um movimento de apagamento e marginalização dos povos africanos, nascidos em diáspora ou não, e seus feitos, em detrimento dos cidadãos brancos. Essa visão e conduta eurocêntrica, não só deturpa uma construção séria e emancipadora da educação, como coíbe e destitui identidades e caminhos para a ascensão social, cultural e financeira: onde não há a possibilidade do ecoar e do narrar das histórias negro africanas, não há possibilidades de constituição da memória e de posicionamentos políticos atrelados às experiências do continente e em diáspora. (NASCIMENTO, 2002).

Ao fazer com que alunos e alunas, sejam eles negros e negras ou não, conheçam apenas um único caminho epistemológico, no caso centrado no amálgama das experiências europeias, o sistema se movimenta a favor do projeto de aniquilação das identidades, memórias, culturas e humanidade do afro descendente no Brasil.

Neste sentido, prescinde vislumbrar e construir novos referenciais, como também analisar a realidade escolar identificando em cada componente da prática educativa diária (ação pedagógica dos professores, cultura escolar cotidiana, currículo, relações escolares, recursos materiais didáticos e rituais pedagógicos) características que são fundamentais para a consolidação de uma pedagogia da diversidade corroborando para a construção de uma educação antirracista (ROCHA, 2007, p. 10).

Rocha (2007) destaca uma pedagogia da diversidade que precisa ser refletida desde o currículo às práticas cotidianas. Para tal, há muito já se fazia necessário uma lei, a qual garantisse que as epistemes negras fossem

\footnotetext{
${ }^{4}$ Assume-se enquanto epistemologia a qualificação do conhecimento dos povos em seus processos de produção artística, cultural, científica, espiritual, de reflexão em torno da natureza e do indagativo de processos estabelecidos entre o sujeito, o processo cognitivo e a teoria do conhecimento. Ou seja, a epistemologia como código de mundo decodificado a partir de experiências do homem com o mundo.

${ }^{5}$ Endossamos a nomenclatura defendida por Kaká Werá. De acordo com Werá, escritor, ambientalista e conferencista brasileiro de origem Tapuia, o termo "povos originários" é uma denominação que resgata a cidadania dos que outrora eram chamados de 'índios", "povos indígenas", dentre outros termos, invisibilizando sua história e especificidades como cidadãos.
} 
consideradas efetivadas, a fim de contribuir na construção de uma educação democrática para uma sociedade equânime e engajada. A Lei 10.639/03 instalou a obrigatoriedade do ensino de História e Cultura Afro-Brasileira e Africana, em todas as instâncias educacionais do ensino básico ao superior, a partir da ótica dos negros no Brasil e em África:

Art. 26-A. Nos estabelecimentos de ensino fundamental e médio, oficiais e particulares, torna-se obrigatório o ensino sobre História e Cultura Afro-Brasileira.

$\S 10$ O conteúdo programático a que se refere o caput deste artigo incluirá o estudo da História da África e dos Africanos, a luta dos negros no Brasil, a cultura negra brasileira e o negro na formação da sociedade nacional, resgatando a contribuição do povo negro nas áreas social, econômica e política pertinentes à História do Brasil.

$\S 20$ Os conteúdos referentes à História e Cultura Afro-Brasileira serão ministrados no âmbito de todo o currículo escolar, em especial nas áreas de Educação Artística e de Literatura e História Brasileiras.

A hierarquização étnico-racial ainda persiste no mundo considerado descolonizado, no caso do Brasil, a implementação da lei 10639/03 configura-se como uma importante estratégia de reconhecimento e acima de tudo, de enfrentamento dessa hierarquização: a inserção do estudo da História da África e dos Africanos na escola é sem dúvida uma forma de reconhecer de forma simbólica e literal cada pedaço de chão por onde nossos antepassados passaram bem como cada pedra carregada por eles sob os indescritíveis maus tratos e violências de toda forma. Essas violências resultaram em uma desigualdade persistente que assola cada pedaço dos corpos negros cujas identidades são muitas vezes invisibilizadas ou apagadas nas concepções e práticas pedagógicas. Dessa forma, a lei 10639/03 é um fundamental para uma educação descolonizadora uma vez que ela apresenta dois eixos principais. $O$ primeiro diz respeito à "valorização da História e cultura africana e afro brasileira, através dos cursos de História, História da Arte, Literatura e Educação Artística, indispensáveis para que a importância da História e Cultura africana no Brasil seja reconhecida." Já o segundo se refere à "Educação para as relações étnico raciais, com o objetivo de estimular o estabelecimento de experiências positivas de superação do racismo" (SILVA; SILVEIRA, 2013, p. 22). Ainda, de acordo com Silva e Silveira,

este segundo objetivo exige que seja promovida uma reflexão crítica a partir de uma Sociologia da Cultura Brasileira, tocando em assuntos delicados e ambíguos da vida brasileira, que dizem respeito a todos os cidadãos, mas de maneiras distintas. Sendo

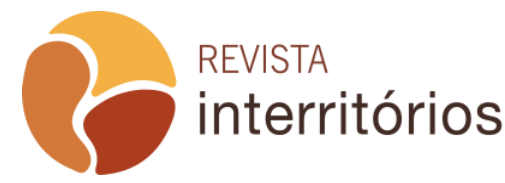

Interritórios | Revista de Educação Universidade Federal de Pernambuco, Caruaru, BRASIL | V.6 N.12 [2020] 
assim, uma discussão conceitual crítica se impõe, pois se trata de selecionar conceitos para uma discussão, mas de uma forma que o contexto social cultural e político dessa discussão informe os conceitos (SILVA; SILVEIRA, 2013, p. 22).

$\mathrm{Na}$ próxima sessão será abordados desafios que cercam a implementação da Lei em questão. Pontua-se que essa ocorrência alimenta a marginalização de assuntos de cunho étnico-raciais e a discussão da existência ou não dos racismos, dos preconceitos, e das discriminações baseado na cor, no fenótipo (NASCIMENTO, 2002; 2017).

\section{Desafios e entraves: a (não) aplicação da lei 10.639/03}

Persiste 0 fato de que ainda não foram superadas as construções sustentadoras do racismo brasileiro, como o mito da democracia racial (FREYRE, 1933), por exemplo, em que isso, por sua vez, determina boa parte dos entraves na aplicação do tema em tela. Junto a essa ocorrência, Ré (2013, p. 41), "Cadernos - Desafios Implementação da Lei 10.698/03", aponta mais outros obstáculos a serem superados pelos educadores para o desenvolvimento da educação para as relações étnico-raciais: junto com "a falta de conteúdos previstos nas leis, nos currículos de formação inicial dos(as) professores (as)", está, também o "investimento ainda insuficiente na formação continuada dos educadores, e a pequena disponibilidade de livros e materiais didáticos sobre a temática nas escolas".

Embora algumas situações possam comprometer o desempenho dos educadores no cumprimento da Lei 10.639/03, é importante que esses não se isentem da responsabilidade de construir uma pedagogia interdisciplinar e crítica (pautada na justiça social), se desafiando a romper com as limitações e possibilitando que a educação para as relações étnico raciais seja realidade em todas as disciplinas e suas diretrizes. Nesse sentido, faz-se necessário, que não só os professores, como também as instituições educacionais, revertam "essa situação adversa tecendo novas propostas, fazendo frente às situações desumanizantes a que as crianças, adolescentes, jovens e adultos negros estão expostas no ambiente" de formação (ROCHA, 2007, p. 14).

Reverter tal situação é repensar as práticas docentes, as quais devem trabalhar as contribuições da cultura e história afro-brasileira e africana de forma respeitosa e verdadeira, comprometida com a denúncia das diversas formas de opressões, sejam elas no material didático, na sala de aula, nas informações veiculadas, ou no cotidiano escolar (ROCHA, 2007). Considerando a implementação da Base Nacional Comum Curricular no sistema educacional brasileiro, através de discussões que iniciaram em 2014, temos uma

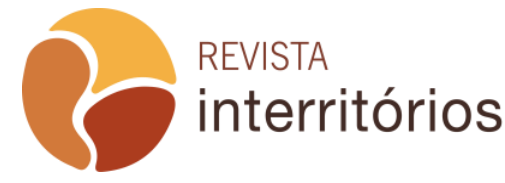

Interritórios | Revista de Educação Universidade Federal de Pernambuco, Caruaru, BRASIL | V.6 N.12 [2020] 
preocupação em enfatizar a importância de se revisitar a lei 10639/03 visto que ela agora precisa dialogar com a Base Nacional Comum Curricular implantada em 2018.

a Base Nacional Comum Curricular (BNCC) é um documento de caráter normativo que define o conjunto orgânico e progressivo de aprendizagens essenciais que todos os alunos devem desenvolver ao longo das etapas e modalidades da Educação Básica. (BRASIL, 2016, p. 7).

A leitura desse trecho nos incita a pensar no que pode ser considerado como "aprendizagem essencial". Dessa forma, a lei 10639/03 é de suma importância para que a história e cultura africana sejam priorizadas nas práticas curriculares que acolhem uma educação intercultural. Destarte, a compreensão de uma educação intercultural, racial e crítica como 'aprendizagens essenciais' para os alunos pode ser um grande desafio considerando o cenário político atual marcado por um conservadorismo neoliberal, conforme Prado denuncia

sabe-se que, historicamente, as dificuldades para os profissionais da Educação no Brasil sempre foram muitas, porém, nos últimos anos, a tarefa de exercer a docência e o desenvolvimento do pensamento, de forma livre e crítica, tem se tornado um desafio diário. A onda ultraconservadora que desponta mundo afora (...) parece fazer com que a herança colonial, religiosa e militar brasileira esteja mais viva do que nunca, uma agenda política em direção ao aprofundamento das desigualdades e das injustiças sociais (PRADO, 2019, p. 202203).

A partir das palavras de Prado, compreendemos que é preciso que o professor continue exercendo a docência pautada na coragem e resiliência. Em outras palavras, ele precisa enfrentar uma estrutura política e econômica que tenta contradizer ou invalidar documentos como a BNCC e a própria lei 10639/03. Hall (2006) problematiza essa homogeneização da seguinte forma

o sujeito, previamente vivido como tendo uma identidade unificada e estável, está se tornando fragmentado; composto não de uma única, mas de várias identidades, algumas vezes contraditórias ou não resolvidas. Correspondentemente, as identidades, que compunham as paisagens sociais "lá fora" e que asseguravam nossa conformidade subjetiva com as "necessidades" objetivas da cultura, estão entrando em colapso, como resultado de mudanças estruturais e institucionais. (HALL, 2006, p.11) 
As mudanças estruturais e institucionais ocorrem a partir de uma perspectiva descolonizadora que não se alinhe às paisagens sociais brancas. Por isso, descontruir essas paisagens só é possível a partir de uma Educação Intercultural. Um dos recursos que o professor comprometido com uma educação antirracista possui é o documento intitulado "Educação antirracista: caminhos abertos pela Lei Federal $n^{\circ} 10.639 / 03$ ". Este documento foi publicado no ano de 2005 pela Secretaria de Educação Continuada, Alfabetização e Diversidade (Secad/MEC). Ele foi estruturado em três partes, a saber Contextualização da Lei no 10.639/03, Por uma educação antirracista, Dimensões do ensino da trajetória dos povos negros no Brasil.

A segunda seção (Por uma educação antirracista) apresenta estudos e orientações para o enfrentamento do racismo na escola de modo que ele não seja "compreendido como ações inerentes à interação entre as crianças" (CAVALLEIRO, 2005, p. 73). Cavalleiro (2005, p. 70) ainda problematiza a situação vivida em muitas escolas brasileiras valendo-se das palavras de Munanga

o preconceito incutido na cabeça do professor e sua incapacidade em lidar profissionalmente com a diversidade, somando-se ao conteúdo preconceituoso dos livros e materiais didáticos e às relações preconceituosas entre os alunos de diferentes ascendências étnico-raciais, sociais e outras, desestimulam o aluno negro e prejudicam seu aprendizado (MUNANGA, 2001, p.8).

As práticas pedagógicas fazem parte de múltiplos sistemas complexos por onde o racismo nasce e se (r)estrutura. É posto com isso, que muitos professores reproduzem as teorias e práticas que Ihes foram ensinadas nos cursos de graduação os quais nem sempre acompanham e legitimam novos conhecimentos, especialmente no que tange às questões de raça. Com isso, 0 excerto anterior é um alerta urgente para educadores.

Por isso, repensar as práticas é repensar a abordagem: uma das óticas que auxiliam tal estudo é a perspectiva da Educação Intercultural, a qual justificase, ainda mais, no Brasil devido ao seu caráter multifuncional atrelado ao fato de que diversos grupos culturais consolidaram e consolidam a cor, forma e jeito nas terras outrora colonizadas. Uma das maiores contribuições da lei 10639/03 é legitimação de uma educação intercultural crítica que não apague as identidades afro-diaspóricas e que não minimize o racismo infligido a esses indivíduos.

\section{A educação intercultural crítica na (re)constituição das identidades}

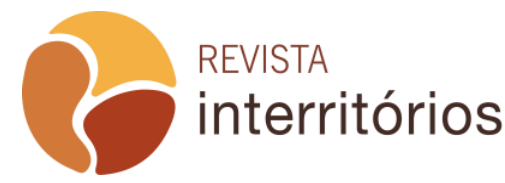

Interritórios | Revista de Educação Universidade Federal de Pernambuco, Caruaru, BRASIL | V.6 N.12 [2020] 
Conforme Hall (2006), o estudo de cultura tem como maior objetivo a obtenção do autoconhecimento cultural, o que, segundo ele, é uma forma de resolver conflitos interculturais e desenvolver potencial humano. Nessa direção, como dito, a magnitude e a nítida necessidade do estudo Intercultural crítico se justifica, sobretudo, no Brasil devido a história de formação desse país, a qual foi consolidada a partir de diferentes grupos culturais, mas que, devido ao eurocentrismo/racismo, mantém um processo contínuo de marginalização, violação, apagamento e silenciamento de corpos, experiências, práticas e epistemologias negras em detrimento das europeias (NASCIMENTO, 2017).

Esse fato elucida a sobrevivência do racismo na sociedade brasileira, e aprofundando, brevemente sobre esse tema, conforme Moore (2007, p. 22), pode-se compreender o racismo como um fenômeno constituído "na história dos conflitos entre povos decorrentes das diferenças fenotípicas", consistindo em "uma dinâmica determinada pela história e não pela ideologia" (MUNANGA, apud. MOORE, 2007, p. 16). Nessa perspectiva, o racismo "aparece nitidamente como a forma de consciência mais violenta e abrangente, porquanto ele implica uma vontade e intenção de extermínio do Outro Total.", ou seja, objetivando o extermínio do outro em sua totalidade física, simbólica, cultural, espiritual e estrutural (MOORE, 2007, p. 244).

De acordo com o cientista social,

desde seu início, na Antiguidade, o racismo sempre foi uma realidade social e cultural pautada exclusivamente no fenótipo, antes de ser um fenômeno político e econômico pautado na biologia. O fenótipo é um elemento objetivo, real, que não se presta à negação ou à confusão. É ele, não o gene, que configura os fantasmas que nutrem o imaginário social; que serve de linha de demarcação entre os grupos raciais e como ponto de referência em torno do qual se organizam as discriminações 'raciais' (MOORE, 2007, p. 22).

Com isso, "o racismo confere, ipso facto, vantagens e privilégios exclusivos segundo a posição que se ocupe na hierarquia de uma ordem racializada", segregando e elevando determinados grupos (brancos), frente a outros (africanos e povos originários, por exemplo) (MOORE, 2007, p.255). O racismo, segundo Moore (2007, p. 248), dificilmente se sustentaria sem três dinâmicas que se encontram na gênese de seu fenômeno, as quais estão imbricadas, e que mesmo distintas, são interconexas e interdependentes. A primeira instância, conforme o autor, é o processamento simbológico

pelo qual uma coletividade, convertida em um grupo dominante, segrega uma consciência grupal para uma rejeição de uma

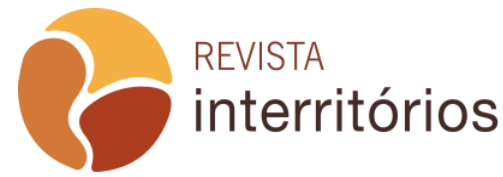

Interritórios | Revista de Educação Universidade Federal de Pernambuco, Caruaru, BRASIL | V.6 N.12 [2020] 
alteridade especificamente fenotípica, com a finalidade de exercitar uma dominação grupal permanente sobre essa última (MOORE, 2007, p. 247).

A segunda instância é a "organização da sociedade numa ordem sistêmica, segundo um critério especificamente fenotípico, para exercer uma gestão monopolista dos recursos globais, de modo a excluir o grupo dominado e subalternizado" (MOORE, 2007, p. 248). Já a última das três dinâmicas, consiste na

elaboração de estruturas intelectuais normativas (ideologias), especificamente destinadas a: primeiro, regulamentar as relações entre dominados e dominantes; segundo, inculcar um sentimento permanente de derrota no segmento subalternizado; e terceiro, criar uma convicção narcísica de inquestionável superioridade permanente $\mathrm{e}$ invulnerabilidade no setor dominante (MOORE, 2007, p. 248).

É importante ressaltar que essas estruturas podem dialogar com a definição de racismo institucional apresentado por Almeida (2018, p.40), ao dizer que "no caso do racismo institucional, o domínio se dá com o estabelecimento de parâmetros discriminatórios baseados na raça, que servem para manter a hegemonia do grupo racial no poder".

Nesse contexto, o sistema educacional, segundo Nascimento (2017, p. 113), "funciona como aparelhamento de controle nesta estrutura de discriminação". Conforme o autor, nesse sistema, "em todos os níveis do ensino brasileiro - primário, secundário, universitário - o elenco das matérias ensinadas (...), constitui um ritual da formalidade e da ostentação das salas da Europa" (NASCIMENTO, 2017, p. 133). Pouco se fala das contribuições dos povos africanos e originários na formação da sociedade, e tão pouco se faz valer dessas experiências, processos epistemológicos nas práticas educacionais.

Diante disso, uma abordagem intercultural nas práticas pedagógicas se faz indispensável, sobretudo tendo em vista o histórico escravocrata brasileiro e a permanência do racismo como estrutural e institucional em sua sociedade, junto do sentimento de inferioridade frente a Europa e aos Estados Unidos. Tal abordagem surge como um meio de assegurar a valorização de todos os grupos e o desenvolvimento de novas práticas pedagógicas. Assim, segundo Fleuri,

a educação intercultural, no contexto das lutas sociais contra os processos crescentes de exclusão sociais inerentes à globalização econômica, propõe o desenvolvimento de estratégias que promovam a construção de identidades particulares e o reconhecimento das diferenças (FLEURI, 1999, p. 277). 
A educação intercultural pauta-se na eclosão do enriquecimento mútuo. Enriquecimento ocasionado pelo conflito, o qual é visto como educativo pelas suas diferenças. Esse conflito é resultante da interação dos grupos culturais, e que por isso, no contexto da educação intercultural, deve ser valorizado: reconhecendo os sentidos e as identidades culturais de cada grupo frente a geração de um crescimento cultural nas práticas sociais e pedagógicas. Mesmo quando os Parâmetros Curriculares Nacionais para a Educação Fundamental elegeram, no Brasil, a Pluralidade Cultural (BRASIL, 1997) como sendo um dos temas curriculares transversais, há, ainda, dificuldades na construção e na elaboração de trabalhos pedagógicos no cerne das relações interculturais. Tal situação demonstra, ainda, como as três dinâmicas do racismo se encontram fortes e ativas nas relações da sociedade, em que, segundo Fleuri (1999), pouquíssimo se discutiu sobre uma proposta educativa que considere efetivamente a complexidade cultural do Brasil.

Espera-se que os educadores que trabalhem o ensino intercultural, tenham outra postura na sala de aula e um olhar diferenciado para o aluno, e até mesmo para o livro didático. Esse educador, e essa educadora precisam sustentar um posicionamento crítico, elaborar métodos e técnicas de desenvolvimento pedagógico a fim de legitimar as culturas de origem de cada indivíduo. Ser crítico, nesse aspecto, é reafirmar o compromisso com questões sociais, pois é preciso desenvolver junto com cada aluno a capacidade de analisar, refletir e questionar cada processo do ensino aprendizagem e dos impactos sociais. Assim, trabalhar de forma crítica as questões propostas é colaborar para a formação política do educando, para a (re)estruturação da vida social e para promoção de uma educação antirracista.

A formação da sociedade brasileira se deu de forma violenta ocasionando destituições de certas identidades culturais. Fleuri (1999) destaca que o ensino intercultural no Brasil deve, por isso, problematizar as imagens até então construídas, fomentando mecanismos e práticas educativas auxiliadoras da autoconsciência dos sujeitos marginalizados, e o incentivo aos movimentos sociais.

Para arquitetar a relação de culturas diferentes é preciso um projeto educativo intencional. A educação intercultural permite a interação, não só de culturas, mas dos sujeitos, os quais a fazem (todos os dias). Ela modifica também o horizonte, realocando o aluno, possibilitando que educando saia de sua zona de conforto, do seu status quo, promovendo uma experiência profunda e complexa.

Salienta-se, por isso, a importância da Lei 10.639/03 ser construída junto de um ensino intercultural, e ou antirracista, pois nessa abordagem, "a cultura do outro" não é reduzida a um objeto de estudo a mais, ela é vista, antes, como um

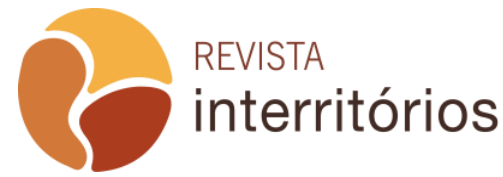

Interritórios | Revista de Educação Universidade Federal de Pernambuco, Caruaru, BRASIL | V.6 N.12 [2020] 
modo próprio de um grupo ver e interagir com a realidade, expande-se a consciência para perceber que a cultura é uma demonstração concreta de práticas e costumes de um determinado grupo étnico que precisa ser compreendidas e respeitadas. Por isso, a educação intercultural exige transformações na forma de educar, por se tornar essencial no combate aos estigmas causados pela a homogeneização e marginalização, que de acordo com Fleuri (2001) é a própria diluição das identidades e apagamento das culturas declaradas como inferiores.

Por fim, pensar uma proposta de educação intercultural e antirracista é importante, sobretudo para ajudar na constituição da autonomia dos grupos marginalizados. É de extrema importância que tais mudanças mirem o respeito recíproco entre diferentes grupos identitários e se desenvolvam de maneira que contribuam para o crescimento e nunca para a perda de identidade. Na seção seguinte, buscar-se-á elucidar de que maneira a aplicação da Lei 10.639/03 corrobora para a (re)constituição das identidades na diáspora africana, fomentando ideias de pertencimento, na perspectiva de Nobles (2009).

\section{Eu não sou daqui: memórias, identidades e epistemologias}

Uma parte da história Africana é marcada por um evento denominado diáspora que define o deslocamento forçado de grandes massas populacionais originárias para todo o globo terrestre, como mão de obra a ser aniquilada. Esse processo, por sua vez, categoriza o que Marimba Ani (1994) conceituou como Maafa6: o holocausto africano, o grande desastre, o maior crime já cometido na história e pela humanidade. Denominamos como afrodiásporicos, toda a população africana deslocada no tempo e no espaço e que nas diásporas teceram sumos acerca de suas histórias e realidades, experiências, processos espirituais, socio econômicos, culturais e políticos, em que mesmo embrenhados em diferentes espaços não deixam de ser africanos (NASCIMENTO, 2002).

Nessa perspectiva, Nobles (2009, p.277), ao examinar o povo africano em toda a diáspora, detalhou que, coletivamente, precisamos "voltar atrás e reconstituir o que esquecemos". Ao ressaltar isso, Nobles sinaliza para o fato de que, coletivamente, esquecemos ou, de modo mais precioso, o opressor tentou esvaziar das mentes negras africanas o significado de ser africano, e por isso de ser humano. Ao fazer silêncio às vozes negras, o ocidente altera percepções

\footnotetext{
${ }^{6}$ Segundo do Marimba Ani (1994), o termo Maafa refere-se à era Européia do comércio de escravos e o seu respectivo efeito sobre os povos Africanos e seus descendentes, em que mais de 100 milhões de pessoas perderam suas vidas e foram então assaltados de forma sistemática e contínua por meio do anti-Africanismo institucionalizado. Em síntese, Maafa define o grande sofrimento dos povos Africanos nas mãos de Europeus e seus descendentes.

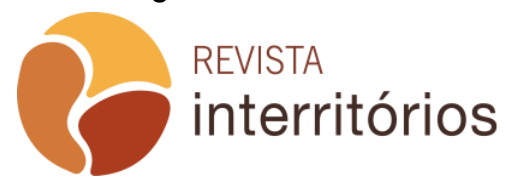

Interritórios | Revista de Educação Universidade Federal de Pernambuco, Caruaru, BRASIL | V.6 N.12 [2020]
} 
ancestrais fundamentais para a constituição das identidades dos povos negros. Esse esquecimento, intencional, é a continuidade do processo de colonização e a efetivação das três dinâmicas do racismo aqui discutidas (NOBLES, 2009).

Com isso, uma vez esquecido, ou colocado a esquecer, os verdadeiros fundamentos epistemológicos que constroem o significado de ser e se fazer humano, percebe-se que, nesse instante, toda a forma de construção do negro em diáspora passa a se dar a partir de, ou mirando, vivências, experiências e identidades eurocêntricas. É nessa teia, que Nobles (2009, p. 284) pontua o estado permanente de descarrilhamento e desafricanização que os negros se encontram, haja vista que "o caminho do desenvolvimento africano em termos de socialização, vida familiar, educação, formas de conhecer a Deus, padrões de governo, pensamento filosófico profundo", tais como as "invenções científicas e técnicas foi desencarrilhado pela invasão e dominação estrangeira". A metáfora do descarrilhamento é importante, haja vista que quando há o desencarrilhamento,

o trem continua em movimento, entretanto fora dos trilhos; o desencarrilhamento cultural do povo africano é difícil de detectar porque a vida e a experiência continuam.

A experiência do movimento (ou progresso) humano continua, e as pessoas acham difícil perceber que estão fora de sua trajetória de desenvolvimento. A experiência vivida, ou a experiência dos vivos, não permite perceber que estar no caminho, seguindo sua própria trajetória de desenvolvimento, proporcionaria a eles uma experiência de vida mais significativa (NOBLES, 2009, p. 284).

Esse processo destitui identidades culturais, mas em contrapartida a essa lógica colonial, ao trazer para primeiro plano a história e cultura negro africana, atreladas às disciplinas curriculares, a Lei 10639/03 faz em si o ecoar das vozes outrora silenciadas e amordaçadas. Essas, uma vez ecoadas, são por si a fecundação das narrativas africanas e diaspóricas em corpo e energia e em seus filhos; que nesse momento podem, novamente, constituir e gozar da humanidade preta representando alteridade e grandeza. Fazendo valer, assim, as postulações de Nobles (2009), acerca da construção das emancipações dos povos negros em diáspora e no continente, que segundo o autor é sempre coletiva e só é possível caso seja reconstruída no senso do que é ser africano, ou seja, a partir das cosmovisões e cosmologias das culturas africanas e afrobrasileiras (NOBLES, 2009).

Assim, na medida em que se elucida o quão problemático é o apagamento das histórias, mais se compreende a importância de uma educação antirracista para a retomada da consciência dos negros e negras na sociedade contemporânea. Nessa direção, mais uma vez, a Lei 10.639/03, atrelada a

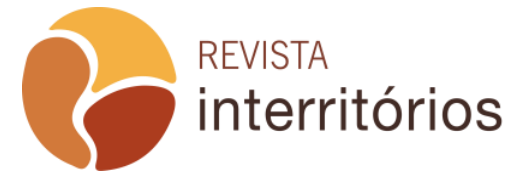

Interritórios | Revista de Educação Universidade Federal de Pernambuco, Caruaru, BRASIL | V.6 N.12 [2020] 
práticas interculturais, possibilita, e reafirma, os processos para a (re)construção das identidades africanas e afro diaspóricas, destituídas no Brasil. Possibilita, sobretudo, na medida em que ao se fazer valer das subjetividades de cada cultura como mecanismo educativo, permite que negros e negras (re)construíam suas identidades junto das experiências ancestrais de seus povos.

A Lei é por isso, uma das próprias possibilidades de encarrilhamento das identidades, destacando as experiências negras como mecanismos epistemológicos para a educação e para as lutas sociais. Atacar a história de um povo, alterá-la ou silenciá-la foi uma das formas que o colono utilizou como maneira de intensificar o processo de dominação aos africanos e aos povos originários. Não contar a história, nas relações africanas e afro-brasileiras, é, nesse sentido, deturpar a importância da ancestralidade/espiritualidade na construção da humanidade, das sociedades e identidades culturais africanas.

Conforme Nobles (2009), o europeu sempre temeu o poder espiritual do africano, tal como refletido nos quilombos e na vivência dos candomblés. Ao reconhecer que o significado do que é ser africano (um espírito vivo consciente e cognoscível) se alimenta de forma livre e contínua em suas cosmovisões e cosmologias, essa prática e presença se estabelecem como um poderoso contraponto à socialização do racismo; por isso a insistência em apagar a história e cultura negra nas escolas. Uma vez conscientes de suas histórias e aspectos culturais, mais difícil se torna a sustentação do racismo (NASCIMENTO, 2002). Nessa perspectiva, a ancestralidade negro africana, tal como suas histórias, atribui aos seres humanos uma condição de poder, exemplificando, mais uma vez, o porquê do apagamento dessas epistemologias (NOBLES, 2009; NASCIMENTO, 2002; 2017).

Conforme Nascimento (2017, p. 133), "consciência é memória e futuro", dessa maneira, quando não há referência ao africano ou negro, não há possibilidade de constituição das identidades. A Lei 10.639/03 demonstra que, junto da importância da referência negra no sistema educacional, é necessário que tal presença colabore para o sentimento de pertencimento, e não afastamento. Uma educação antirracista pauta-se em menções fidedignas das experiências africanas, pois, uma vez deturpadas começa a haver um movimento contrário: algumas práticas alimentam a auto rejeição do aluno e da aluna negra, que por serem condicionados a um sentido de alienação da identidade negra, poderão buscar se assimilar ao máximo com os indivíduos e culturas brancas, tais como de seus valores, estéticas e noções de sociabilidade (NASCIMENTO, 2017).

A Lei 10.639/03 é a possibilidade de atualização do que Nobles (2009, p. 277) desenhou para a diáspora e o continente: "embora tenha sido pavoroso o ataque contra o senso de ser dos africanos, o branco não conseguiu destruir 0 africano dentro de nós". Por isso, neste artigo, buscou-se fomentar possíveis

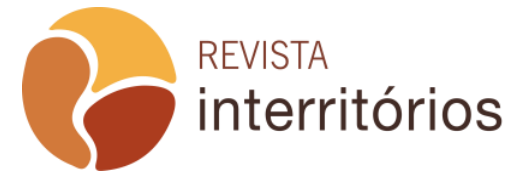

Interritórios | Revista de Educação Universidade Federal de Pernambuco, Caruaru, BRASIL | V.6 N.12 [2020] 
reflexões acerca da importância da Lei aqui analisada. Nesse sentido, infere-se que, para que se altere a percepção, ou a crença, que a colonização instaurou no senso imaginário dos negros, é fundamental a luta pela efetivação da Lei aqui discorrida, como contraponto do projeto colonial.

Por fim, as palavras de Sousa (2005, p. 118) sintetizam muitas de nossas aspirações ao longo desse artigo no sentido de que "as leis por si só nada garantem, pois temos muitas que não passam de letras mortas. Mas se as conquistamos precisamos fazê-las valer, tornando-as de fato um instrumento de combate ao racismo".

\section{CONSIDERAÇÕES FINAIS}

A Lei 10.639/03, ao se centrar nas experiências de povos africanos como ferramenta epistemológica para a educação para além do processo de colonização, permite a construção de uma consciência intercultural crítica, ligada a estudos e estudiosos a respeito da colaboração da história e cultura africana na formação das diversas sociedades. A sua efetivação assegura que negras e negros, tais como suas histórias, narrativas e aparelhos científicos, possam protagonizar um espaço outrora deturpado e embranquecido pela perspectiva e prática colonialista. Por outro lado, o ensino intercultural é uma ferramenta crucial na medida em que cultiva a construção de uma relação crítica, de reconhecimento das diferenças culturais, para a promoção de identidades sociais, buscando a solidariedade e a interação entre elas ao passo que se estabelece um reconhecimento das estruturas opressivas e se constrói um espaço para desmantelar essas estruturas presentes na economia, saúde, educação e até no sistema penal, etc.

Em suma, desenvolver uma educação antirracista, a partir do enfrentamento de toda e qualquer ação violenta, é necessário para fomentar novas possibilidades da construção das identidades, tal como para 0 reconhecimento, a valorização e a emancipação da população negra no processo do constructo social. Assim, para que a referida lei obtenha êxito, as práticas pedagógicas nas escolas, para além de denunciar toda forma de opressão baseada na raça, na identidade de gênero, nas condições sexuais, nas relações de classe e opções religiosas, precisam trazer para o centro das discussões dos conteúdos narrativas múltiplas, de diferentes povos com suas contribuições. Embora não estejamos falando de uma tarefa fácil, leis como a 10639/03, ancorados nas premissas de documentos prescritivos como a BNCC, podem legitimar esse empreendimento pedagógico. Isso contribui para que 0 espaço escolar deixe de ser um celeiro de manutenção do racismo, para se tornar, de fato, um ambiente de discussão, valorização e emancipação racial que

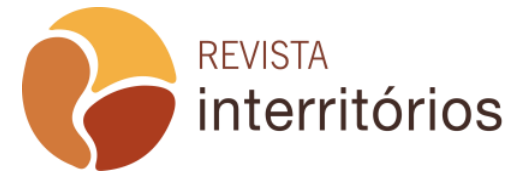

Interritórios | Revista de Educação Universidade Federal de Pernambuco, Caruaru, BRASIL | V.6 N.12 [2020] 
acontece por meio da ação pautada nos documentos educacionais e leis de forma crítica e responsiva.

\section{REFERÊNCIAS BIBLIOGRÁFICAS}

ALMEIDA, Silvio Luiz de. O que é racismo estrutural?. Belo Horizonte (MG): Letramento, 2018.

ANI, MARIMBA. Yurugu: uma crítica africano-centrada do pensamento e do comportamento cultural europeu. Trenton, NJ: África World Press, Inc.,1994.

BRASIL, Lei ํo 10639 de 9 de janeiro de 2003. Ministério da Educação. Diretrizes Curriculares Nacionais para a Educação das Relações Étnicos Raciais e para o Ensino de História e Cultura Afro-Brasileira e Africana. MEC/SECAD. 2005. Disponível em: http://www.planalto.gov.br/ccivil_03/leis/2003/110.639.htm. Acesso em 09 Janeiro 2020.

BRASIL, Lei no 10639 de 9 de janeiro de 2003. Ministério da Educação. Base Nacional Curricular Comum. Disponivel em: /http://basenacionalcomum.mec.gov.br/. 2016. Acesso em 08 de junho de 2020.

BRASIL, Lei no 10639 de 9 de janeiro de 2003. Educação Antirracista: caminhos abertos pela Lei Federal n. 10.639/03. Brasília: Ministério da Educação/SECAD, 2005.

CASTRO, Yeda Pessoa de. Falares Africanos na Bahia: Um Vocabulário AfroBrasileiro. 1. ed. Rio de Janeiro: Academia Brasileira de Letras, 2005.

CAVALLEIRO, Elaine. Discriminação racial e pluralismo em escolas públicas da cidade de São Paulo. In: SECRETARIA DE EDUCAÇÃO CONTINUADA, ALFABETIZAÇÃO E DIVERSIDADE (SECAD). Educação antirracista: caminhos abertos pela lei federal no 10.639/03. Brasília: Ministério da Educação, Secretaria de Educação Continuada, Alfabetização e Diversidade (MEC-SECAD), 2005. p. 65-104.

FLAUZINA, Ana Luiza Pinheiro; Corpo negro caído no chão: o sistema penal e o projeto genocida do estado. Dissertação de Mestrado em Direito. UNB, 2006. Disponível em: https://repositorio.unb.br/handle/10482/5117. Acesso em 09 de junho, 2020. brasileiro. Tese de mestrado em Direito - Universidade de Brasília, Brasília, 2006.

FLEURI, Reinaldo Matias. Educação intercultural no Brasil: a perspectiva epistemológica da complexidade. R. bras. Est. pedag., Brasília, v. 80, n.195, p. $277-$ 289, maio/ago, 1999.

FREYRE, Gilberto. Casa-Grande \& Senzala. Editora: José Olympio. 1933.

HALL, Stuart. A identidade cultural na pós-modernidade. 9a ed., Rio de Janeiro: DP\& ${ }^{\underline{a}}, 2006$.

MOORE, Carlos. Racismo e sociedade: novas bases epistemológicas para entender o racismo. Belo Horizonte: Mazza Edições, 2007.

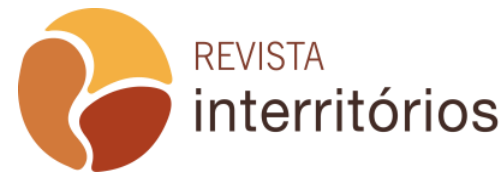

Interritórios | Revista de Educação Universidade Federal de Pernambuco, Caruaru, BRASIL | V.6 N.12 [2020] 
MUNANGA, Kabengele (Org.). Superando o Racismo na Escola. Brasília: Ministério da Educação, Secretaria de Educação Continuada, Alfabetização e Diversidade, 2007.

MUNANGA, Kabengele (Org.). Apresentação. In: MUNANGA, K (org.). Superando o racismo na escola. Brasília: Ministério da Educação, Secretaria de Educação, 2001.

NASCIMENTO, Abdias. O genocídio do negro brasileiro: processo de um racismo mascarado. 2 ed. São Paulo: Perspectiva, 2017.

NASCIMENTO, Abdias. O quilombismo. 2 ed. Brasília/Rio de Janeiro: Fundação Palmares/ OR Editor Produtor Editor, 2002.

NOBLES, W. W. Sakhu Sheti: retomando e reapropriando um foco psicológico afrocentrado. In: E. L. Nascimento (Org.). Afrocentricidade: Uma abordagem epistemológica inovadora (Coleção Sankofa: Matrizes Africanas da Cultura Brasileira, 4, p. 277-297). São Paulo: Selo Negro, 2009.

PARDO, Fernando da Silva. Decolonialidade e ensino de línguas: perspectivas e desafios para a construção do conhecimento corporificado. Revista Letras Raras. Campina Grande, v. 8, n. 3, p. Port. 200-221 / Eng. 198-218, 2019.

PINHEL, André Marega; COLONTONIO, Eloise Médice; SILVA, Célia Cristina da; SILVEIRA, Marcos Silva da Silveira. Desafios da implementação da Lei 10.639/03. Universidade Federal do Paraná: Curitiba, 2013.

RÉ, Veroni Salete Del., SILVEIRA Marcos Silva A naturalização dos educadores frente aos problemas étnico-raciais, a discriminação e a desigualdade racial. In: PINHEL, A, M. et al (org). Cadernos Desafios na implementação da Lei 10.639/03. Curitiba: UFPR, 2013.pp 38-49.

ROCHA, Rosa Margarida de Carvalho. Educação das relações étnico-raciais: pensando referenciais para a organização da prática pedagógica. Belo Horizonte: Mazza Edições, 2007.

SOUSA, Francisca Maria do Nascimento. Linguagens escolares e reprodução do preconceito. In: SECRETARIA DE EDUCAÇÃO CONTINUADA, ALFABETIZAÇÃO E DIVERSIDADE (SECAD). Educação antirracista: caminhos abertos pela lei federal $\mathrm{n}^{\circ}$ 10.639/03. Brasília: Ministério da Educação, Secretaria de Educação Continuada, Alfabetização e Diversidade (MEC-SECAD), 2005.p.66 -120. 